\title{
Pseudo-elliptic narrow bandpass filter using shorted coupled-line of higher order design
}

\author{
Mohd Nasiruddin Hushim ${ }^{1}$, Norfishah Ab Wahab ${ }^{2}$, Muhammad Farid Abdul Khalid ${ }^{3}$, \\ Tn. Syarifah Atifah Tn. Mat $\mathrm{Zin}^{4}$ \\ 1,2,3 Faculty of Electrical Engineering, Universiti Teknologi MARA, Malaysia \\ ${ }^{4}$ Department of Mathematics, Science \& Computer, Politeknik Banting Selangor, Malaysia
}

\section{Article Info}

Article history:

Received Oct 1, 2018

Revised Nov 30, 2018

Accepted Dec 15, 2018

\section{Keywords:}

Bandpass filter

Coupled-line

Cross coupling

Narrowband

Tranmission zero

\begin{abstract}
This paper presents an implementation of quarter wavelength single-shorted coupled-lines for narrow bandpass filter application. It is shown as a new way of creating a single resonance bandpass filter by inter-connected of two single-shorted quarter wavelength coupled-line sections. By adding more single-shorted coupled-line into the configuration, the form of halfwavelength resonator can increase the degree of order of the filter. For the design of 4th order resonator, the coupled-lines are arranged interconnected to each other forming five-fingers lines layout. Due to the interconnection of the coupled-lines, transmission zeros appear at the two stopbands which improves the selectivity of the filter response. Investigation on the parametric of the 4th order resonator is conducted to observe the controlling parameters and it's realiability responses of the resonator. For compactness, five-fingers meandered lines is proposed. It is found that the size of the meandered lines resonator was successfully reduced by $33 \%$ compared to the five-fingers straight lines resonator of the same order. For validation of concept, the 4 th order meandered lines resonator was designed at $1 \mathrm{GHz}$ and fabricated on RO3210 microstrip substrate with characteristics given as $\mathrm{h}=1.27 \mathrm{~mm}, \varepsilon \mathrm{r}=10.2$ and $\tan \delta=3 \times 10-3$. The measurement results show good agreement with the simulation results.
\end{abstract}

Copyright $@ 2019$ Institute of Advanced Engineering and Science. All rights reserved.

Corresponding Author:

Mohd Nasiruddin Hushim, Faculty of Electrical Engineering, Universiti Teknologi MARA, 40450 Shah Alam, Selangor, Malaysia.

Email: nasiruddin_my@ieee.org

\section{INTRODUCTION}

Increasing consumer demand on the modern wireless devices required the sensitivity and capabilities of the communication system. As one of the important role in the modern communication, the filtering element was design based on the specific requirement in line with the desired technology communication field [1]. Researches and developments on the filter designs had focused on improving the filter performances in areas such as insertion loss, bandwidth, selectivity and etc [2]. Numerous topology designs of bandpass filter including the parallel coupled line were introduced depended on the characteristics requirement of the application used.

The classical parallel coupled-line was proposed by Cohn in 1958 [3]. Further researches for improvement on this topology still going on until today [4-5]. The classical parallel coupled-line topology structure consist of coupled-line with series connection. As the degree of order depends on the number of halfwavelength resonator, this will increase the total length of the filter. This is due to the fact that more coupled-lines are connected in series to the base topology [6-8]. Furthermore, in terms of the selectivity of the filter, there are no transmission zero offer in the classical parallel coupled-line response [9]. 
Further research and development on the coupled-line topology were explored by researcher to improve the performance and cababilities of the filter to fulfill the modern communication system that require compact size, accurate and very high selectivity of the filter. In order to achieved compactness and reduce size of the filter, several techniques were used such as patch capacitor [10], folded design [11], meandered pattern [12-13], additional of active elements [14] and defected ground structure (DGS) [15].

In this paper, a new topology bandpass filter using two single-shorted coupled-lines is proposed, where a section of the single-shorted coupled-line are inter-connected to form half wavelength resonator. By introducing new coupled-lines inter-connected to the base cell will form new half wavelength resonator that leads to the number of degree of the filter. Therefore, the $4^{\text {th }}$ order bandpass filter can be formed by inter-connecting three new single-shorted coupled-line into the basic configuration. When compared to the conventional parallel copled-line, the advantage of this topology is that, it exhibits transmission zeros at the stopbands of the filter response. Furthermore, by employing five-finger straight-lines arrangement of the single-shorted coupled-lines, will optimize the axis surface area of the filter. To reduce the size, meander technique is applied to the design. The five-fingers meander-lines offers approximately response when compare to the five-finger straight-lines filter design.

\section{FILTER TOPOLOGY}

The proposed new coupling structure depicted in Figure 1(a) consists of end-shorted half wavelength resonator. The half wavelength resonator is created from the inter-connection of two singleshorted quarter wavelength coupled-line sections with two sets of odd- and even-mode characteristics impedances. This topology creates a single resonance bandpass filter response as depicted in Figure 1(b). The resonator is designed at $1 \mathrm{GHz}$ with the value of impedances; $\mathrm{Z}_{\mathrm{oe} 1}=69 \Omega, \mathrm{Z}_{\mathrm{oo1}}=43 \Omega$ and, $\mathrm{Z}_{\mathrm{oe} 2}=76 \Omega, \mathrm{Z}_{\mathrm{oo} 2}=47 \Omega$.

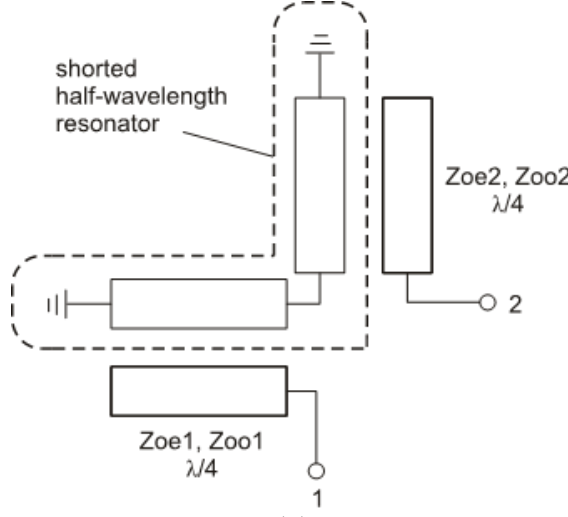

(a)

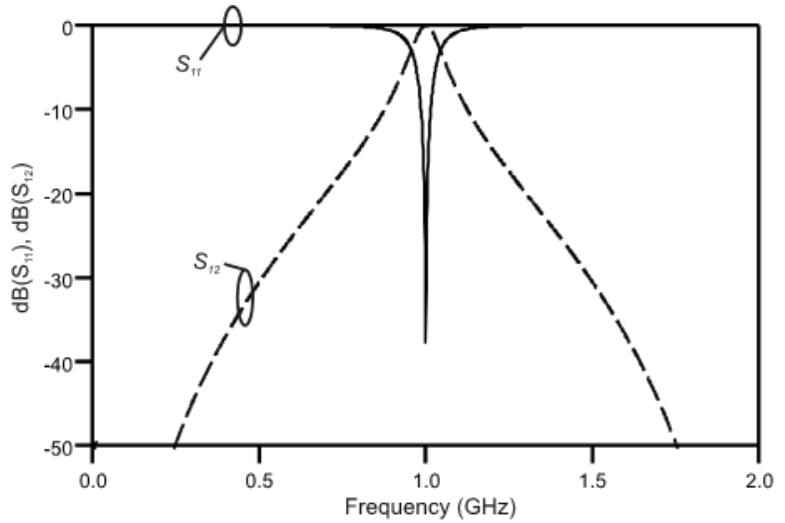

(b)

Figure 1. (a) Schematic and (b) Ideal frequency response for end-shorted half wavelength resonator

To further explore the concept, the base topology can be inter-connected with additional couplelines for higher order filter design. With additional of $n$ numbers of single-shorted coupled-lines, $n+1$ order bandpass filter can be created.

To proof the concept, additional of $3^{\text {rd }}$ and $5^{\text {th }}$ coupled-lines are added to the base cell to create $2^{\text {nd }}$ and $4^{\text {th }}$ order bandpass filters as shown in Figure 2(a) and 2(b) respectively. With these arrangements, it can be seen that the half wavelength resonators are created in such a way that the shorted-end and open-end resonators are arranged in alternate manner. Furthermore, with fingers layout arrangement of the coupledlines, side-by-side surrounding the axis up to $4^{\text {th }}$ order, it maintaines the size of the resonators at $1 / 4 \lambda \times 1 / 2 \lambda$. This leads to optimizing the surface area of the filter.

The resonators are designed at $1 \mathrm{GHz}$, and the impedance values for both resonators are tabulated in Table 1. The designs are simulated using fullwave electromagnetic simulation tool and the ideal responses of the resonators are as shown in Figure 3(a) and 3(b). 


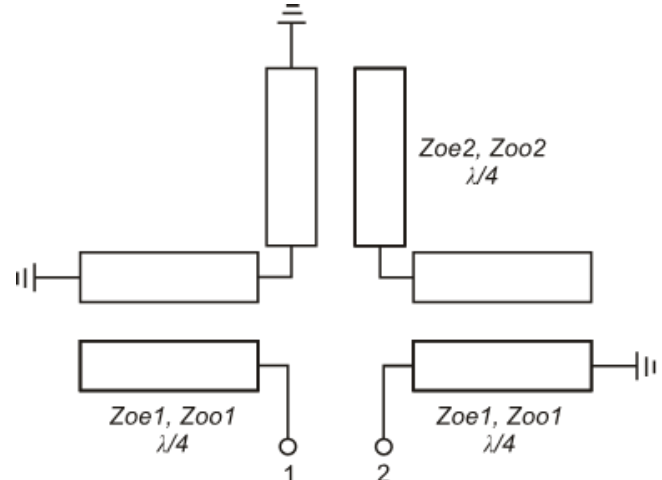

(a)

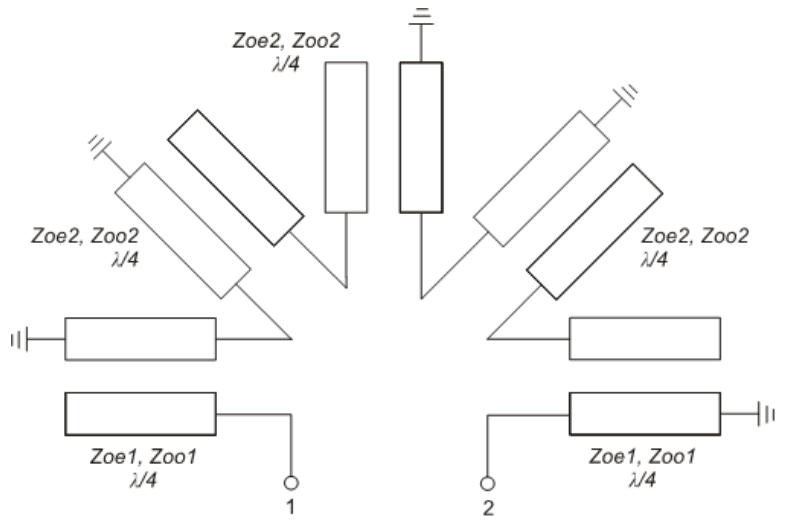

(b)

Figure 2. Fingers bandpass filter layout based on inter-connected single-shorted coupled-lines resonators, for (a) $2^{\text {nd }}$-order filter with two half wavelength resonator and (b) $4^{\text {th }}$-order filter with four half wavelength resonator

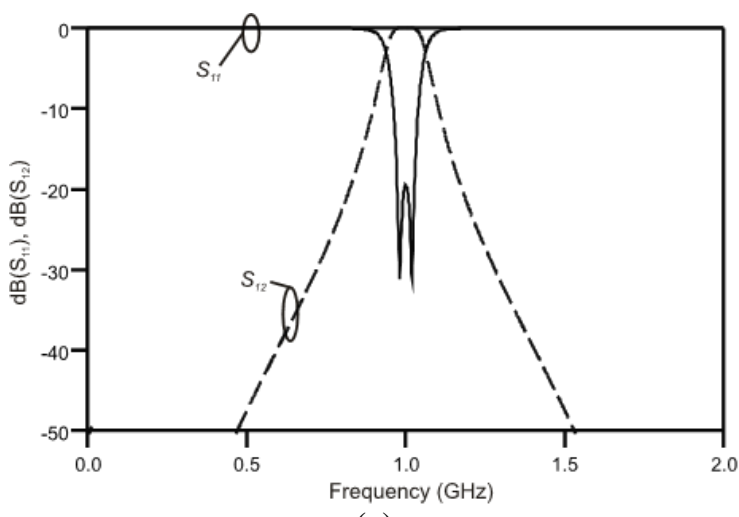

(a)

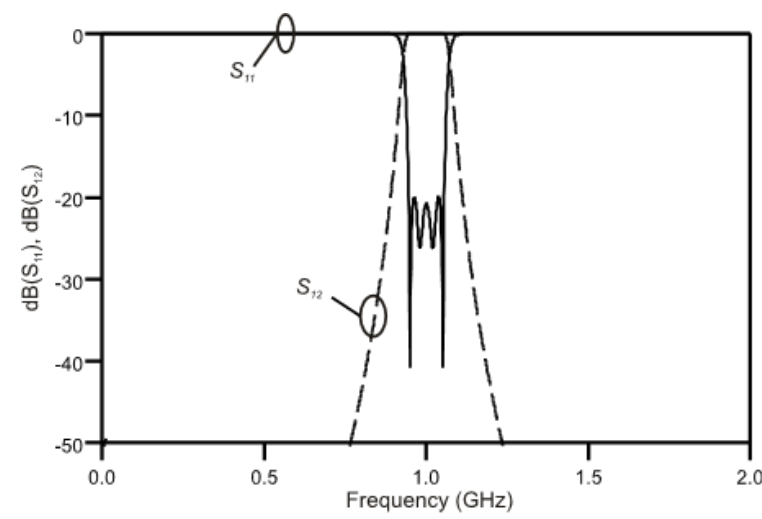

(b)

Figure 3. Ideal frequency response of the (a) $2^{\text {nd }}$ and (b) $4^{\text {th }}$ order bandpass filter

Table 1. Even- and Odd-Mode Characteristic Impedances of the $2^{\text {nd }}$ and $4^{\text {th }}$ Order Resonators

\begin{tabular}{ccccccc}
\hline & $Z_{\mathrm{oe} 1}$ & $Z_{\mathrm{oo} 1}$ & $Z_{\mathrm{oc} 2}$ & $Z_{\mathrm{oo} 2}$ & $Z_{\mathrm{oe} 3}$ & $Z_{\mathrm{oo} 3}$ \\
\hline $2^{\text {nd }}-$ order filter & $95 \Omega$ & $46 \Omega$ & $38 \Omega$ & $29 \Omega$ & - & - \\
$4^{\text {th }}$-order filter & $74 \Omega$ & $31 \Omega$ & $50 \Omega$ & $37 \Omega$ & $60 \Omega$ & $47 \Omega$ \\
\hline
\end{tabular}

As shown in Table 1, the above impedances' values of the $2^{\text {nd }}$ and $4^{\text {th }}$ order resonators are chosen through their parametric study. From the parametric study, one can observe the variations of the filter response and investigate the behavior and controlling parameters of the resonator.

\section{3. $4^{\text {TH }}$ ORDER FILTER VARIATION OF ELECTRICAL RESPONSES}

This section presents the parametric study of the $4^{\text {th }}$ order resonator design. For realization of resonator on microstrip substrate, one has to choose a suitable characteristic impedance value that can be realized on the substrate [1]. Based on this information, the odd- and even-mode impedance values of the single-shorted coupled-lines of the $4^{\text {th }}$ order resonators are established. Since the layout is symmetrical, hence only three instead of five sets of coupled-lines have to be optimized for symmetrical bandpass response.

For the variation parametric study, each value of the parameters is set in the range of $20 \Omega$. All the

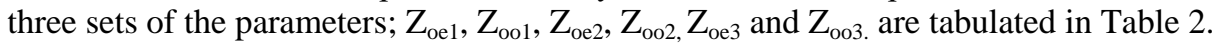


Table 2. Variation Parameter for Ideal $4^{\text {th }}$ Order Bandpass Filter Response

\begin{tabular}{cccc}
\hline Graph & Parameter & Min Value $(\Omega)$ & Max Value $(\Omega)$ \\
\hline Figure 4 & $\mathrm{Z}_{\mathrm{oe} 1}$ & 65 & 85 \\
Figure 5 & $\mathrm{Z}_{\mathrm{oo} 1}$ & 20 & 40 \\
Figure 6 & $\mathrm{Z}_{\mathrm{oe} 2}$ & 45 & 65 \\
Figure 7 & $\mathrm{Z}_{\mathrm{oo} 2}$ & 25 & 45 \\
Figure 8 & $\mathrm{Z}_{\mathrm{oe} 3}$ & 60 & 80 \\
Figure 9 & $\mathrm{Z}_{\mathrm{oo} 3}$ & 30 & 50 \\
\hline
\end{tabular}

Figure 4 shows the variation of $Z_{\text {oel }}$ from $65 \Omega$ to $85 \Omega$ while fixing the other impedances at ideal value $\left(Z_{\mathrm{oe} 1}=74 \Omega, Z_{\mathrm{oo} 1}=31 \Omega, Z_{\mathrm{oe} 2}=50 \Omega, Z_{\mathrm{oo} 2}=37 \Omega \quad Z_{\mathrm{oe} 3}=60 \Omega\right.$ and $\left.Z_{\mathrm{oo} 3}=47 \Omega\right)$. It can be seen that $Z_{\mathrm{oe} 1}$ influences on bandwidth, insertion loss and return loss of the filter. As shown in Figure 5, the variation values of $Z_{\mathrm{oo} 1}$ from $20 \Omega$ to $40 \Omega$ seen the changes of bandwidth compare to the $Z_{\mathrm{oe} 1}$. For the variation values of $Z_{\mathrm{oe} 2}, Z_{\mathrm{oo} 2} Z_{\mathrm{oe} 3}$ and $Z_{\mathrm{oo} 3}$ are shown in Figure $6,7,8$ and 9 respectively.
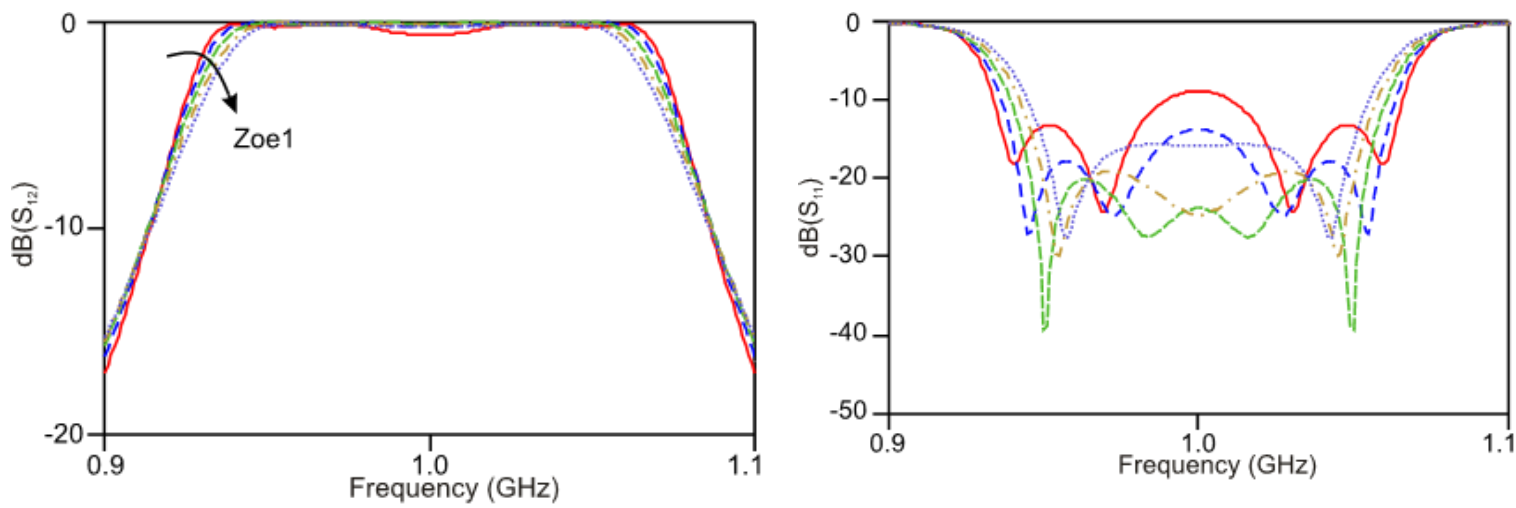

Figure 4. Ideal variation values of $\mathrm{Z}_{\mathrm{oe} 1}$ from $65 \Omega$ to $85 \Omega$ and the electrical responses
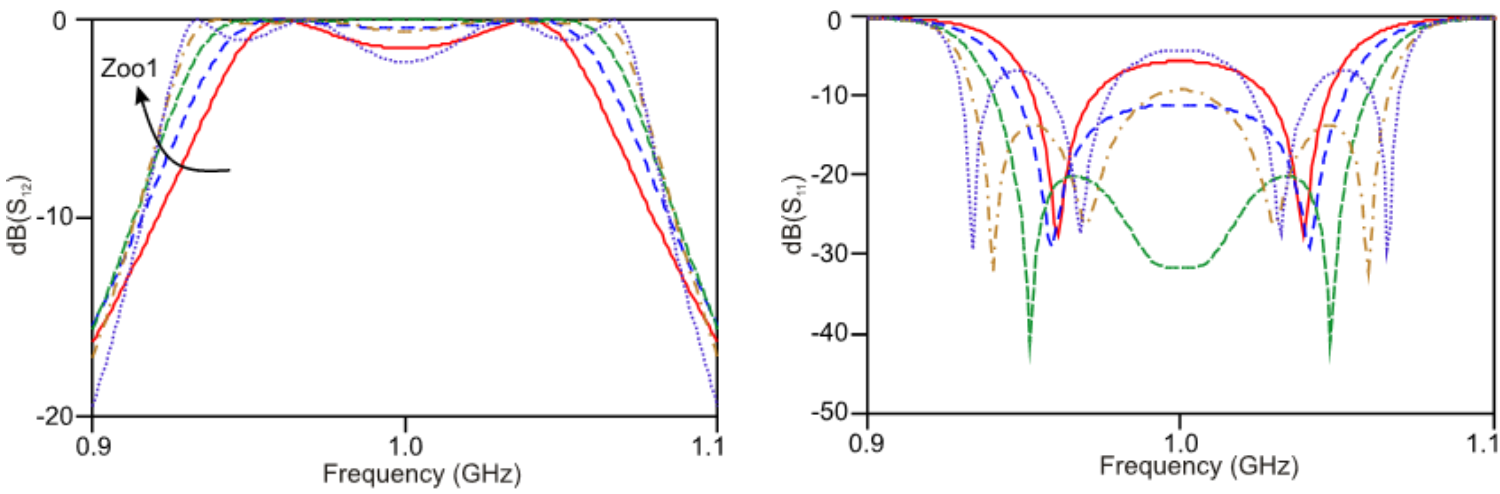

Figure 5. Ideal variation values of $\mathrm{Z}_{\mathrm{oo} 1}$ from $20 \Omega$ to $40 \Omega$ and the electrical responses

The observation of variation responses when the value of $2^{\text {nd }}$ coupled-line varied as tabulated in Table 2. As depicted Figure $6 \& 7$, both of the parameters influence on the bandwith. However, the controlling of $\mathrm{Z}_{\mathrm{oo} 2}$ on bandwidth is more dominant compare to $\mathrm{Z}_{\mathrm{oe} 2}$. The coupling coefficient, $\mathrm{k}$ for $1^{\text {st }}$ coupled-line is 0.41 while $2^{\text {nd }}$ coupled-line is 0.15 . Noted that, lower coupling coefficient resulting to weaker coupling effect that influenced on bandwidth. 

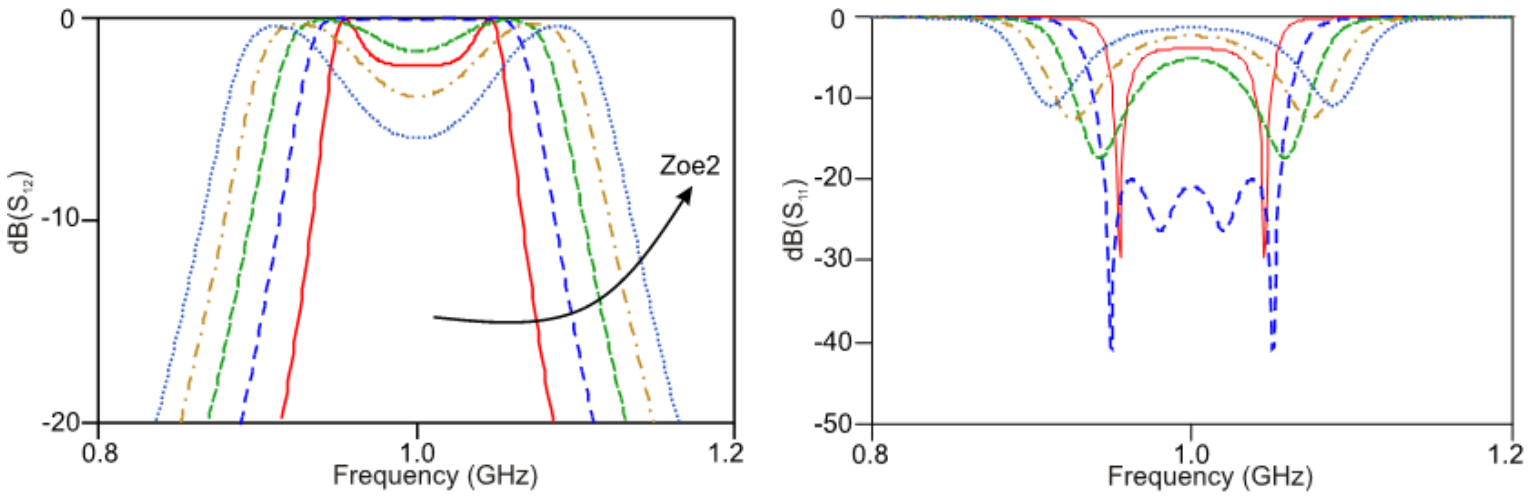

Figure 6. Ideal variation values of $Z_{\mathrm{oe} 2}$ from $45 \Omega$ to $65 \Omega$ and the electrical responses
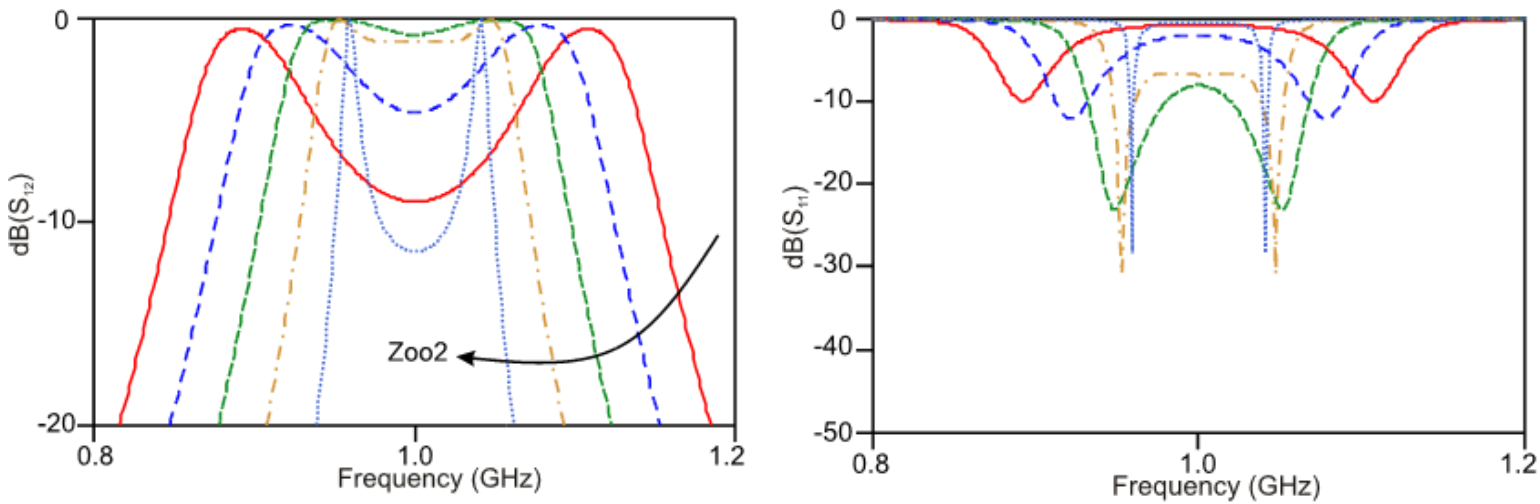

Figure 7. Ideal variation values of $\mathrm{Z}_{\mathrm{oo} 2}$ from $25 \Omega$ to $45 \Omega$ and the electrical responses

Next, observation is performed on a $3^{\text {rd }}$ coupled-line. The variation of electrical responses for $Z_{\text {oe } 3}$ and $Z_{\mathrm{oo} 3}$ are shown in Figure 8 and 9 respectively. The increment of $Z_{\mathrm{oe} 3}$ or decrement of $Z_{\mathrm{oo} 3}$ would increase the bandwidth but at the same time degrade the return and insertion losses due to mismatch of impedances.
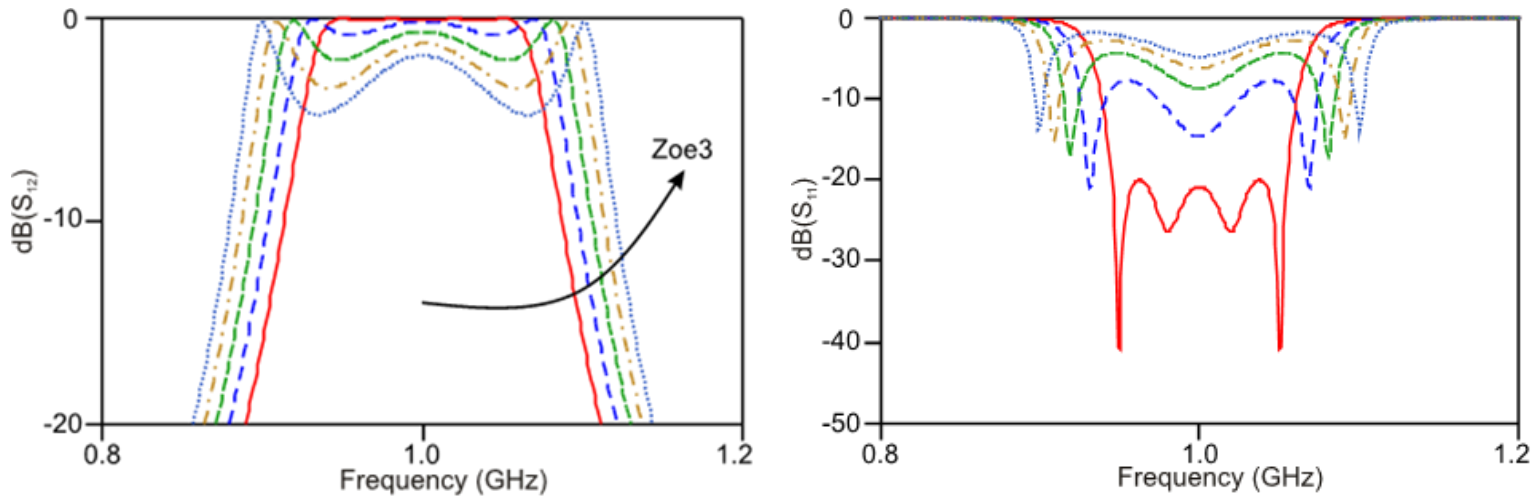

Figure 8. Ideal variation of $\mathrm{Z}_{\text {oе } 3}$ from $60 \Omega$ to $80 \Omega$ and the electrical responses 

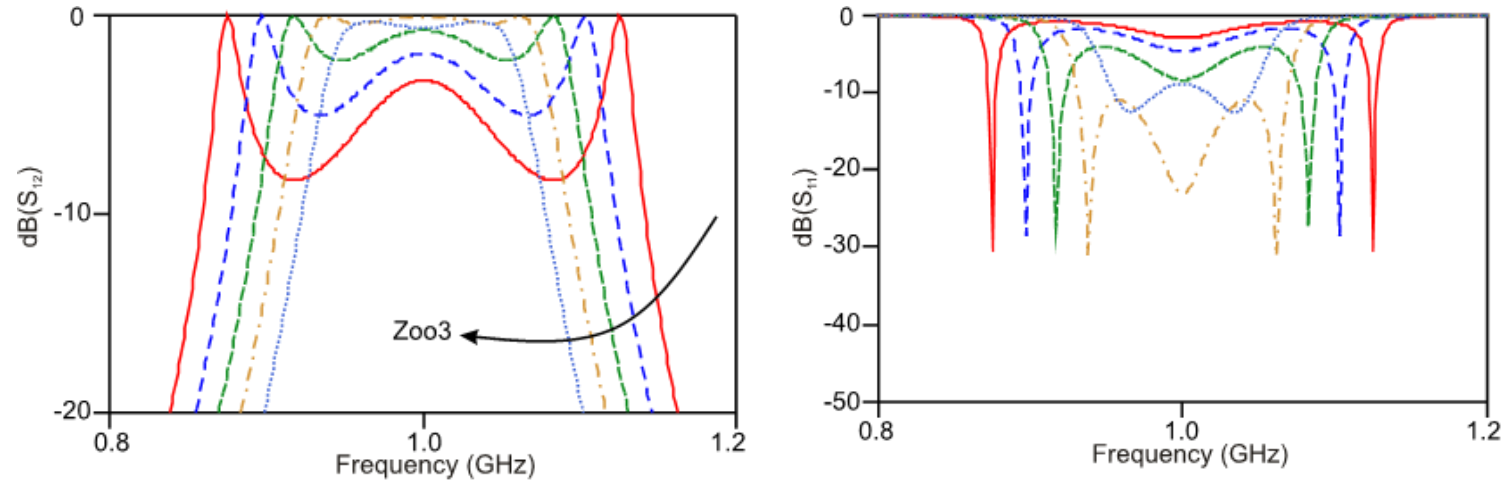

Figure 9. Ideal variation values of $\mathrm{Z}_{\mathrm{oо} 3}$ from $30 \Omega$ to $50 \Omega$ and the electrical responses

Based on the illustrate ideal responses of parametric variation study for the $4^{\text {th }}$ order bandpass resonator, it can be said that the odd- and even-mode impedances of the $2^{\text {nd }}$ and $3^{\text {rd }}$ single shorted coupledlines dominantly controlled the bandwidth of the resonator with variation in the range of 5\%. Hence, this resonator design is suitable for narrowband bandpass fiter applications. In terms of impedance matching, all the parameters need to be optimized accordingly for best results to obtain bandpass response.

\section{4. $\quad 4^{\mathrm{TH}}$ ORDER FILTER REALIZATION}

This section presents the layout and implementation of higher order bandpass filter design for $4^{\text {th }}$ order resonator using microstrip technology. The first design is based on five-fingers straight-lines layout with area dimensions of $58.1 \mathrm{~mm} \times 44.7 \mathrm{~mm}$. For miniaturization, all the five fingers are meandered and the area dimensions achieved $44.9 \mathrm{~mm}$ x $38.6 \mathrm{~mm}$, resulting to approximation of $32.6 \%$ size of reduction. Both layouts of the five-fingers straight-lines and five-fingers meandered-lines are shown in Figure 10 and Figure 11 respectively. The resonators are designed at $1 \mathrm{GHz}$, simulated by using full wave electromagnetic simulator. For implementation, the five-fingers meandered-lines resonator was realized on Roger RO3210 microstrip substrate $\left(\mathrm{h}=1.27 \mathrm{~mm}, \varepsilon_{\mathrm{r}}=10.2, \tan \delta=3 \times 10^{-3}\right)$.

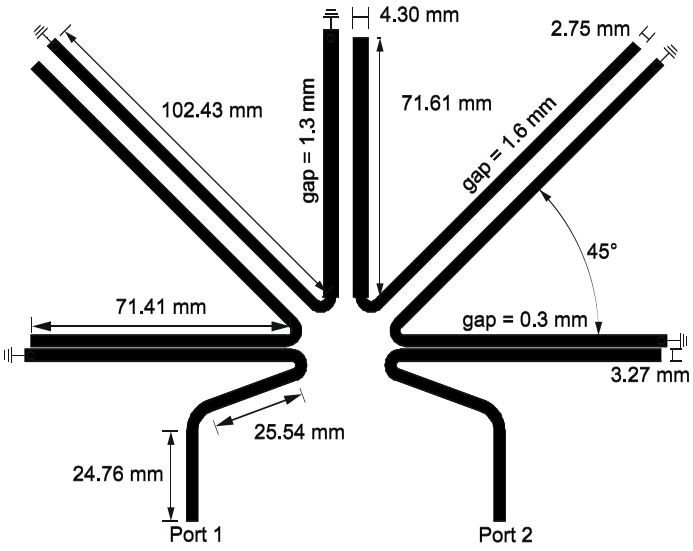

Figure 10. Schematic layout $4^{\text {th }}$ order five-fingers straight-lines bandpass filter

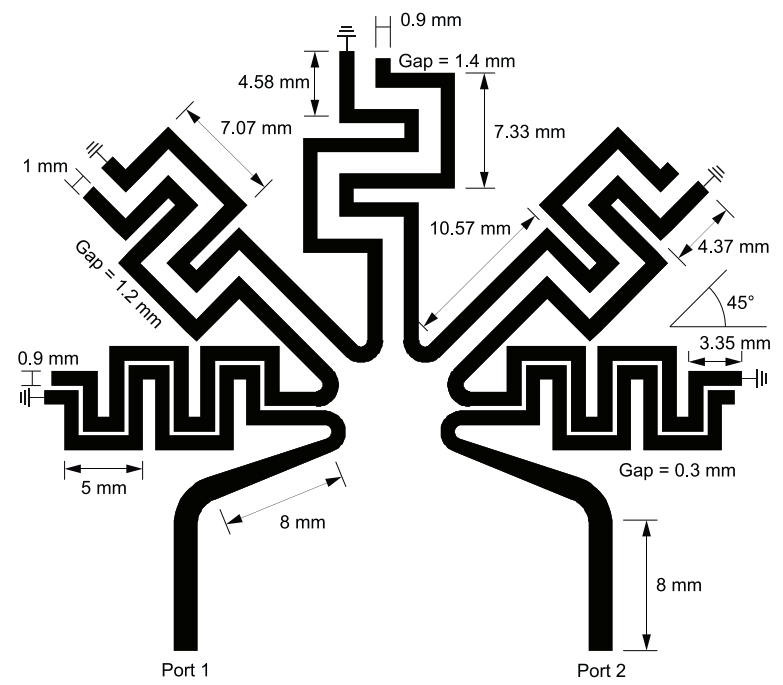

Figure 11. Schematic layout of $4^{\text {th }}$ order five-fingers meandered-lines bandpass filter

Both resonators were successfully simulated. The comparison output of the simulations for fivefinger straight-lines and meandered-lines is depicted in Figure 12. Both passband responses are centered at 1 $\mathrm{GHz}$ with insertion losses less than $3 \mathrm{~dB}$. The effect of the cross couplings occurs from adjacent of the 
coupled-lines in both designs lead to the creation of transmission zeros at both side of passband responses. The presences of transmission zeros contribute to high selectivity bandpass filter responses.

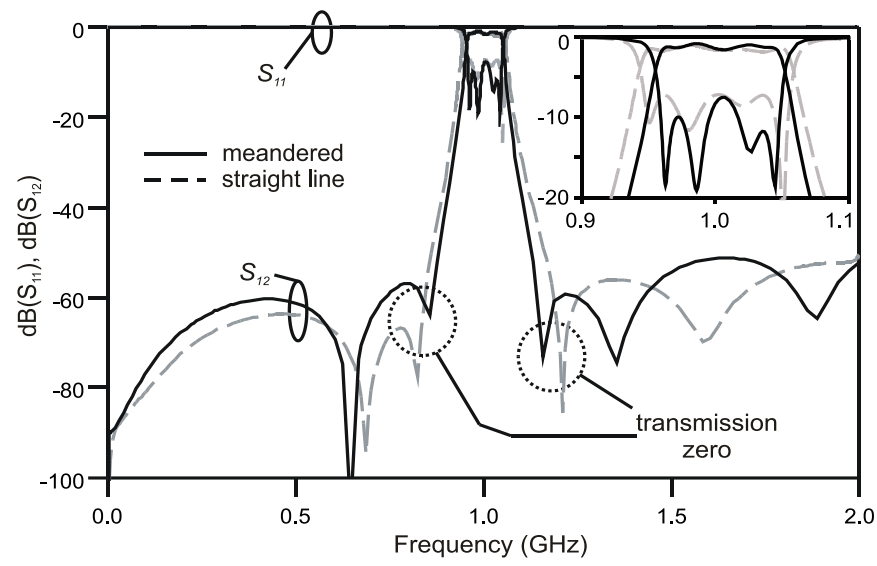

Figure 12. Comparison output of simulation for five-fingers straight-lines and meandered-lines resonator designs

Finally, the $4^{\text {th }}$ order five-fingers meandered-lines resonator was fabricated and measured. Figure 13(a) shows the photograph of the fabricated resonator on RO3210 substrate. The measurement result is compared with simulated and achieved good out-of-band rejection level beyond $50 \mathrm{~dB}$ as depicted in Figure 13(b). The resonance is centered at $1 \mathrm{GHz}$ with $5.2 \%$ relative bandwidth and insertion loss of $3.2 \mathrm{~dB}$. Transmission zeros are found at the upper and lower side of the stopbands. The presence of transmission zeros due to the cross coupling effect among the coupled-lines is advantageous to the design, since it gives high selectivity and good rejection level of the filter response.

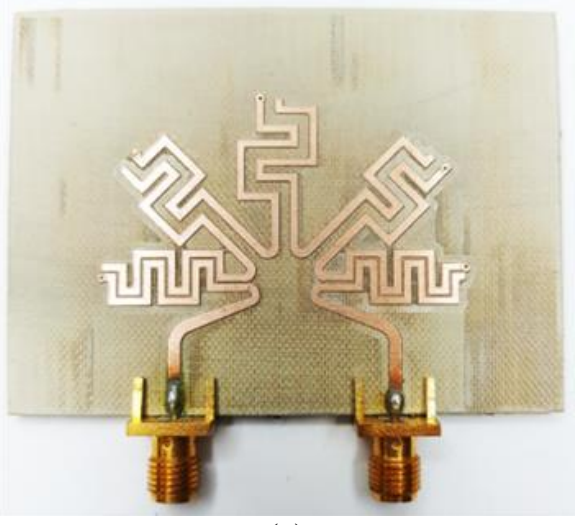

(a)

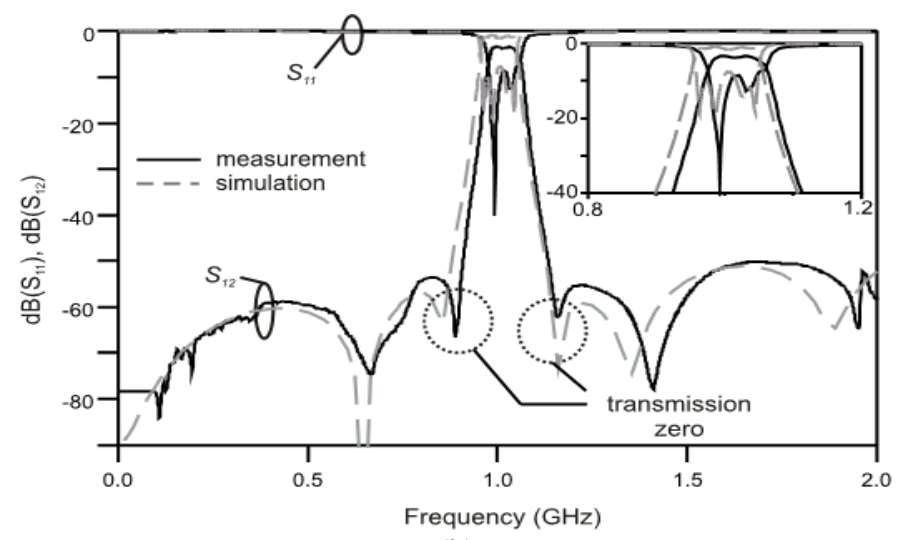

(b)

Figure 13. A 4th order meandered-lines bandpass filter of (a) photograph and (b) simulation and measurement result

\section{CONCLUSION}

A bandpass resonator of single-shorted coupled-line topology was presented. By adding more coupled-line into the base cell, lead to the creation of higher order bandpass filters. Parameter study was conducted for $4^{\text {th }}$ order resonator and was found that the characteristics of the resonator responses can be controlled by varying the impedance of the odd- and even-mode impedances of the coupled-lines. Meander technique was applied on the $4^{\text {th }}$ order five-fingers lines and was successfully reduced the size of the resonator by more than $30 \%$. Finally, the proposed filter of $4^{\text {th }}$ order was realized on the microstrip substrate and the measurement results of the fabricated filters were found to be in good agreement with the simulation 
results. The advantage of this topology is that, tranmission zeros were created on the $4^{\text {th }}$ order bandpass filter response due to cross coupling effect. The occurrence of transmission zeros lead to higher selectivity of the filter and better rejection level.

\section{ACKNOWLEDGEMENTS}

The authors gratefully acknowledge the contributions of M. K. M. Salleh, who passed away in September 2017, for his patience, motivation, support and guidance on this work. This work was supported in part by the Ministry of Higher Education of Malaysia (MOHE) (Grant no: 600-RMI/NRGS 5/3 (3/2013)) and the Institute of Research Management and Innovation (IRMI) of Universiti Teknologi MARA

\section{REFERENCES}

[1] G. L.Matthaei, "Microwave Filters, Impedance Matching network and Coupling Structure." Artech House, Norwood, MA, 1964

[2] V. K. Velidi and S. Sanyal, "Sharp-rejection microstrip bandpass filters with multiple transmission zeros," $A E U$ Int. J. Electron. Commun., vol. 64, no. 12, pp. 1173-1177, 2010.

[3] S. B. Cohn, "Parallel-Coupled Transmission-Line-Resonator Filters," IRE Trans. Microw. Theory Tech., vol. 6, no. 2, pp. 223-231, 1958.

[4] M. B. Zaradny, "On the Novel Approach to Parallel Coupled-Line Bandpass Filters thah Have Diverse Wavelenght Impedance Scaling I/O Transformers," Proc. 25th Int. Conf. "Mixed Des. Integr. Circuits Syst., pp. 291-298, 2018.

[5] M. Naureen, D. K. Choudhary, and R. K. Chaudhary, "Compact metamaterial inspired dual-band bandpass filter using parallel coupled line and circular shaped stub," 2018 3rd Int. Conf. Microw. Photonics, ICMAP 2018, vol. 2018-Janua, no. Icmap, pp. 1-2, 2018.

[6] Xiongjun Shu, Jincai Wen, and Lingling Sun, "Design of $60 \mathrm{GHz}$ parallel coupled-line bandpass filters," in 2015 IEEE 16th International Conference on Communication Technology (ICCT), 2015, pp. 244-247.

[7] A. E. Ferh and H. Jleed, "Design, simulate and approximate parallel coupled microstrip bandpass filter at 2.4 GHz," in 2014 World Congress on Computer Applications and Information Systems (WCCAIS), 2014, no. 1, pp. 1-5.

[8] B. P. Stosic, N. S. Doncov, and A. S. Atanaskovic, "Response calculation of parallel-coupled resonator filters by use of synthesized wave digital network," in 2013 11th International Conference on Telecommunications in Modern Satellite, Cable and Broadcasting Services (TELSIKS), 2013, pp. 253-256.

[9] A. Gunjal, S. R. Gagare, and R. P. Labade, "Bandwidth enhancement in band pass filter (BPF) using microstrip couple lines for WLAN (2.4GHZ) applications," in 2016 International Conference on Electrical, Electronics, and Optimization Techniques (ICEEOT), 2016, pp. 3629-3632.

[10] J. Selga, P. Vélez, M. Orellana, M. Sans, A. Rodriguez, and V. E. Boria, "Size Reduction and Spurious Suppression in Microstrip Coupled Line Bandpass Filters by means of Capacitive Electromagnetic Bandgaps," in 2016 IEEE MTT-S International Microwave Symposium (IMS), 2016, vol. 1, no. 2, pp. 31-34.

[11] T. K. Das and S. Chatterjee, "Spurious Harmonic Suppression in a Folded Parallel- Coupled Microstrip Bandpass Filter by using Triangular Corrugations," 2017 Devices Integr. Circuit, pp. 23-24, 2017.

[12] M. Ali and T. Abbas, "Compact, Meandered-Line Microstrip Bandpass Filter," in 17th IEEE International Multi Topic Conference 2014, 2014, pp. 67-72.

[13] V. K. Killamsetty and B. Mukherjee, "Miniaturised highly selective bandpass filter with very wide stopband using meander coupled lines," Electron. Lett., vol. 53, no. 13, pp. 889-890, 2017.

[14] N. A. Wahab, I. Pasya, M. F. A. Khalid, I. M. Yassin, S. H. Herman, and Z. Awang, "Pseudo-Elliptic Bandpass Filters Using Closed-Loop Resonator," Int. J. Adv. Sci. Eng. Inf. Technol., vol. 7, no. April, pp. 345-351, 2017.

[15] A. Kumar and M. V Kartikeyan, "Design and realization of microstrip filters with new defected ground structure (DGS ),” Eng. Sci. Technol. an Int. J., vol. 20, no. 2, pp. 679-686, 2017. 